\title{
Isolamento e cultivo de neurônios e neuroesferas de córtex cerebral aviar $^{1}$
}

\author{
Carla Rossini Crepaldi², Giovana Krempel Fonseca Merighe², Hélen Julie Laure ${ }^{3}$, \\ José César Rosa ${ }^{3}$, Flávio Vieira Meirelles² e Marcelo de Cerqueira César ${ }^{2 *}$
}

\begin{abstract}
Crepaldi C.R., Merighe G.K.F., Laure H.J., Rosa J.C., Meirelles F.V. \& Cerqueira César M. 2013. [Isolation and culture of neurons and neurospheres from chicken brain cortex.] Isolamento e cultivo de neurônios e neuroesferas de córtex cerebral aviar. Pesquisa Veterinária Brasileira 33(Supl.1):45-50. Laboratório de Neurociência e Proteômica, Faculdade de Zootecnia e Engenharia de Alimentos, Universidade de São Paulo, Av. Duque de Caxias Norte 225, Pirassununga, SP 13635-900, Brazil. E-mail: mccesar@usp.br

Cell culture methods are used for studies of protein interactions in neural cells, helping to detect the interactome of proteins linked to generation of central nervous system diseases. For this reason, neural cells and neurospheres isolated from cortical chicken brain are a current model for studies of neurological diseases, such as epilepsy. Chicken brain has key characteristics on its proteome, with a differential expression of proteins linked to energy metabolism, some of them (VDAC 1 and VDAC 2) play an important role in understanding mechanism of refractory epilepsy. Using the methods described, we found neurospheres, in which cells grow in structures with the ideal diameter of 100-200 $\mu$ m within seven days after isolation. Neurospheres differentiation was obtained after adhesion of these cells to surfaces coated with poly-D-Lysine, detected by migration of fibers inside them. Unlike neurospheres, neurons extended neurites after 11 days of isolation. Here we describe a method to isolate and culture neurons and neurospheres from chicken cerebral cortex. Such "in vitro" model can be utilized on studies of neuronal protein differential expression and interaction. Cultures of isolated neurons represent an accessible model on studies of apoptosis and channel blockers of key proteins linked to brain metabolism.
\end{abstract}

INDEX TERMS: Epilepsy, neuron, neurosphere, interactome, mitochondria, brain, chicken.

RESUMO-- Métodos de cultivo celular são convenientes na realização de análises funcionais de alterações/interações protéicas das células neuronais, auxiliando a decifrar o interactoma de proteínas chaves na neurogênese de doenças do Sistema Nervoso Central. Por esse motivo, culturas de neurônios e neuroesferas isolados do córtex cerebral aviar representam um modelo acessível para o estudo de diversas doenças neurológicas, tal como a epilepsia. A

\footnotetext{
${ }^{1}$ Recebido em 30 de julho de 2013.

Aceito para publicação em 25 de novembro de 2013.

${ }^{2}$ Departamento de Ciências Básicas, Faculdade de Zootecnia e Engenharia de Alimentos, Universidade de São Paulo (USP), Av. Duque de Caxias Norte 225, Pirassununga, SP 13635-900, Brasil. *Autor para correspondência: mccesar@usp.br

${ }^{3}$ Centro de Química de Proteínas, Departamento de Biologia Celular e Molecular e Bioagentes Patogênicos, Faculdade de Medicina de Ribeirão Preto, USP, Rua Tenente Catão Roxo 2501, Ribeirão Preto, SP 14049-900, Brasil.
}

espécie aviar apresenta peculiaridades em seu proteoma neuronal, visto a presença de uma expressão diferenciada de proteínas chaves no metabolismo energético cerebral, algumas destas (VDAC1 e VDAC2) desempenham papel importante na compreensão do mecanismo da epilepsia refratária. A metodologia estabelecida no presente estudo obteve cultivo de neuroeferas, onde as células cresceram tipicamente em aglomerados atingindo, dentro de 7 dias, o diâmetro ideal de 100-200 $\mu \mathrm{m}$. A diferenciação celular das neuroesferas foi obtida após a aderência destas às placas tratadas com poli-D-lisina, evidenciada pela migração de fibras do interior da neuroesfera. Ao contrário das neuroesferas, os neurônios em cultivo extenderam seus neuritos após 11 dias de isolamento. Tal modelo in vitro pode ser utilizado com sucesso na identificação das variáveis neuroproteômicas, propiciando uma avaliação global das alterações dinâmicas e suas interações protéicas. Tal modelo pode ter aplicações em estudos dos efeitos de indutores 
da morte celular e bloqueadores de canais de membrana mitocondriais em proteínas chaves do metabolismo energético cerebral.

TERMOS DE INDEXAÇÃO: Epilepsia, neurônio, neuroesferas, interactoma, mitocôndria, cérebro, córtex cerebral aviar.

\section{INTRODUÇÃO}

A epilepsia é uma desordem cerebral crônica que afeta $1 \%$ da população mundial e é caracterizada por convulsões recorrentes, materializada por uma atividade neuronal anormalmente excessiva ou sincrônica do cérebro (Fabene et al. 2013). Tal desordem neurológica afeta funções físicas, mentais e comportamentais e está associada a maiores riscos de morte prematura causada por injúrias pós-traumáticas, status epilepticus, suicídio, pneumonia e morte súbita, contabilizando 1,4\% de mortalidade da população mundial. Já na população canina a epilepsia é a doença neurológica com a ocorrência mais comum, sendo estimada e uma frequência de 0,5 a 5,7\% (Monteiro et al. 2012).

0 cérebro representa somente $2 \%$ da massa corpórea total, no entanto este consome $20 \%$ do oxigênio e glicose fornecidos pelo sangue, sendo a transmissão sináptica a principal responsável pelo elevado gasto energético proveniente da oxidação da glicose (Escartin \& Rouach 2013). Para atender à elevada demanda energética, as mitocôndrias apresentam uma atividade intensa no tecido cerebral; ressalta-se que a presença de desordens mitocondriais é observada em $14 \%$ dos pacientes epilépticos adultos. Destes, $65 \%$ estão relacionados à causa metabólica/estrutural, enquanto os demais 35\% dos casos são associados às ocorrências genéticas (Finsterer et al. 2013).

Durante a crise convulsiva há um aumento do fluxo glicolítico, no mínimo três vezes superior à taxa basal do cérebro. Durante este período de hiperexcitabilidade, novos níveis regulatórios são estabelecidos por diversos metabólitos, tais como as enzimas fosfofrutoquinase e hexoquinase, que são coordenadamente ativadas. Sendo estes dois sítios enzimáticos os principais pontos de controle da glicólise no tecido cerebral, a habilidade do cérebro em manter o fornecimento adequado das reservas energéticas e de oxigênio é de grande importância para distinguir condições convulsivas das isquêmicas (Sacktor et al. 1966).

A VDAC (voltage dependent selective anion channel) atua como o principal transportador na membrana mitocondrial externa, tendo uma importante função na produção energética, pelo controle do tráfico de metabólitos, e é reconhecida como proteína-chave na apoptose mediada pela mitocôndria (Pastorino \& Hoek 2008). Além disso, serve como sítio de ligação da hexoquinase à mitocôndria, fornecendo acesso preferencial ao ATP intramitocondrial. Esta interação entre a VDAC e a hexoquinase tem consequências metabólicas, uma vez que a fosforilação da glicose pela hexoquinase ligada está relacionada à produção de ATP pela fosforilação oxidativa intramitocondrial (BeltrandelRio \& Wilson 1991, Cerqueira César \& Wilson 1995, 1998, 2002).

Múltiplas isoformas da VDAC foram identificadas em cérebros humanos e murinos (Cerqueira César \& Wilson
2004), bovinos e aviares (Poleti et al. 2010). A super-expressão da VDAC 1 em uma variedade de células promove a morte celular apoptótica (Kroemer et al. 2007), enquanto que a super-expressão da VDAC 2 previne a ativação da proteína pró-apoptótica BAK e inibe a via apoptótica mitocondrial (Cheng et al. 2003). Dessa forma, observa-se em literaturas que a VDAC 1 possui propriedades pró-apoptóticas, enquanto que a VDAC 2, propriedades anti-apoptóticas.

Um dos principais entraves no tratamento da epilepsia é a fármaco-resistência. Estima-se que um terço dos pacientes epilépticos são resistentes aos medicamentos anticonvulsivos (Pohlmann-Eden \& Weaver 2013); além disso, observou-se que a resposta do paciente ao tratamento adicional a uma nova droga é cerca de 3 - 5\% menos eficaz para cada fármaco testado (Margoliash et al. 2010). Jiang et al. (2007) observaram em modelo animal fármaco-resistente um maior nível de expressão da VDAC1 e o menor de VDAC2, resultando em diminuição da produção e translocação do ATP mitocondrial e promoção da apoptose. Condição semelhante do nível de expressão das isoformas da VDAC foi observada na mitocôndria cerebral aviar (Poleti et al. 2010).

Estudos do laboratório foram pioneiros na identificação das proteínas interactantes à VDAC nos complexos protéicos do cérebro bovino, murino e aviar. Na espécie bovina e murina cerca de $50 \%$ das proteínas interactantes com a VDAC encontradas no complexo murino não são observadas na espécie bovina (Crepaldi et al. 2013).

Em resultados ainda não publicados (Crepaldi et al. 2013) identificamos diversas proteínas-chaves no metabolismo energético cerebral interactantes com a VDAC no cérebro aviar, dentre as quais destacamos a ATP sintase subunidade $\alpha$ (ATPA), aldeído deidrogenase (ALDH2), NADH deidrogenase $1 \alpha$ subcomplexo 10, (NDUAA) Aconitase (ACON), Malato deidrogenase (MDH) e a proteína resistente a múltiplas drogas (MRP1). Jiang et al. (2007) observaram diferenças no nível de expressão de tais proteínas em modelos epiléptico fármaco-resitentes, elucidando a falha energética presente durante a crise convulsiva.

As proteínas NDUAA e a ATPA tem uma função importante durante a fosforilação oxidativa mitocondrial, a qual é a fonte de energia primária do metabolismo neuronal. As proteínas ACON e MDH2 fazem parte do ciclo do ácido tricarboxílico na matriz mitocondrial. A superexpressão das proteínas transportadoras MRP1 no tecido epiléptico reduz a quantidade de drogas que atingem os neurônios epilépticos, contribuindo com a fármaco-resistência (Loscher \& Potschka 2002). Tais resultados indicam um metabolismo energético diferenciado no tecido cerebral aviar, auxiliando na compreensão molecular da sensibilidade das aves à epilepsia, justificando assim o seu uso no estudo da relação patologia-epilepsia.

Segundo Scorza et al. (2009) a espécie aviar pode ser um modelo para estudos de epilepsia por mimetizar a condição humana. A Síndrome da Morte Súbita em Epilepsia (SUDEP) é a causa da morte prematura de até $17 \%$ de todos os pacientes com epilepsia (Sowers et al. 2013). Similarmente, as aves sofrem com a Síndrome da Morte Súbita (SDS) caracterizada por uma morte aguda de frangos apa- 
rentemente saudáveis e bem-nutridas, após um abrupto e breve bater de asas (Scorza et al. 2009). Tais similaridades entre a SUDEP e a SDS estão presentes na manifestação comportamental da SDS muito próxima às crises tônico-clônicas e a incidência de anormalidades cardíacas durante e entre as crises.

O modelo embrionário aviar pode ser utilizado em estudos experimentais para avaliar os efeitos de drogas durante o estágio de desenvolvimento embrionário. Além das semelhanças anatômicas, a espécie aviar apresenta bases moleculares que justificam a sua relevância no estudo da resistência a fármacos como modelo animal epiléptico. 0 estudo in vitro de todo o proteoma neuronal contribui para a avaliação das alterações proteicas e dinâmica das interações proteína-proteína.

O cultivo neuronal primário preparado a partir do tecido nervoso aviar representa uma poderosa ferramenta não somente para o estudo da contribuição individual dos neurônios na progressão das doenças, mas também na investigação da importância das células tronco neurais no desenvolvimento e patogênese da doença (Kim \& Magrané 2011). Adicionalmente ao uso da técnica de cultivo neuronal primário há o cultivo de neuroesferas (células tronco neurais) que podem ser usadas como um vetor de moléculas terapêuticas favorecendo a regeneração e/ou neuroproteção.

No presente estudo é estabelecido um método de cultivo, manutenção e diferenciação de células neurais progenitoras e cultivo de neurônios primários de origem aviar.

\section{MATERIAL E METÓDOS}

\section{Cultivo primário de neurônios aviares}

Conforme metodologia proposta por Monnerie et al. (1997), os embriões aviares foram manipulados no $8^{\circ}$ dia de incubação. Os hemisférios cerebrais foram mantidos em solução fosfato salina (PBS) aquecida a $37^{\circ} \mathrm{C}$. Subsequentemente as meninges foram removidas e o córtex delicadamente picotado.

A dissociação enzimática foi realizada a fim de digerir as proteínas da matriz extracelular e as proteínas de junção celular, responsáveis pela adesão célula-célula e célula-substrato. A enzima comumente utilizada é a Tripsina, pois encontra-se ativa dentro da faixa do $\mathrm{pH}$ fisiológico ( $\mathrm{pH}$ 8,0). A tripsinização durou $15 \mathrm{~min}$. e foi mantida a $37^{\circ} \mathrm{C}$. Para paralisar a ação da tripsina, foi acrescentado o dobro do volume inicial do meio DMEM, contendo $20 \%$ de soro fetal bovino (SFB) (Invitrogen) e 1\% de penicilina-estreptomicina (Invitrogen). A seguir centrifugou-se a 735xg durante $10 \mathrm{~min}$.

Em seguida, o sobrenadante foi removido e o pellet ressuspenso em solução de lise $(170 \mathrm{mM}$ de Tris, $170 \mathrm{mM}$ Cloreto de Amônio) mantida em banho-maria a $37^{\circ} \mathrm{C}$ durante $10 \mathrm{~min}$. e posteriormente centrifugada a $184 \mathrm{xg}$ durante $5 \mathrm{~min}$. Tal etapa é opcional, no entanto sua execução é fortemente sugerida visto que as hemácias aviares são nucleadas, mantendo-se por mais tempo em cultivo e consumindo o meio nutritivo priorizado aos neurônios.

Após a centrifugação, o sobrenadante foi descartado e o pellet ressuspenso em meio Neurobasal (Invitrogen) suplementado com 2\% de B-27 (Invitrogen), 0,25\% GlutaMax (Invitrogen), conforme proposto por Ahlemeyer \& Vogt (2005) e filtrado em peneira de nylon $0,22 \mu \mathrm{m}$ (Millipore) a fim de separar as células.

As placas foram preparadas em uma solução de poli-D-lisina (MW 70-150 KDa, Sigma), dissolvida à concentração de 1mg/100 $\mathrm{ml}$ em tampão borato $(0,1 \mathrm{M}, \mathrm{pH} 8,4)$.
A viabilidade celular foi realizada pelo método de exclusão por tripan blue conforme descrito por Ahlemeyer et al. (2002). Células não-viáveis apresentaram a membrana danificada, sendo coradas com tripan-blue, enquanto que células viáveis permaneceram descoradas. A contagem final foi obtida com uma densidade de $1 \times 10^{4}$ céls $/ \mathrm{mL}$ e as células plaqueadas em garrafas de $25 \mathrm{~cm}^{2}$ pré-tratadas com poli-D-lisina. As células foram mantidas em meio de cultivo a $37^{\circ} \mathrm{C}$ e $5 \% \mathrm{CO}_{2}$ e realimentadas com meio de cultivo a cada dois dias.

\section{Cultivo e diferenciação de neuroesferas}

As etapas iniciais do cultivo de neuroesferas, as quais abrangem a manipulação e o processo de digestão enzimática foram realizados conforme descrito anteriormente.

Após a digestão enzimática, o tecido foi dissociado mecanicamente com o auxílio de uma pipeta. As células foram contadas e plaqueadas em $1 \times 10^{5}$ células $/ \mathrm{mL}$ em meio contendo 1:1 DMEM/F-12 (Invitrogen) suplementada com 33mM glicose, $4 \mathrm{mM}$ L-glutamina, $1 \%$ suplemento $\mathrm{N}_{2}$ (Invitrogen), penicilina (50 U/ $\mathrm{ml}$ ) e estreptomicina $50 \mathrm{mg} / \mathrm{ml}$ (Invitrogen) a $37^{\circ} \mathrm{C}$ na presença de $10 \% \mathrm{CO}_{2}$, conforme proposto por Louis \& Reynolds (2010). As neuroesferas alcançaram em 7 dias o tamanho necessário para serem utilizadas em experimentos ou replicadas em outras placas tal como proposto por Kearns et al. (2003).

A diferenciação das células progenitoras em neurônios ocorre espontaneamente quando plaqueadas em substrato adequado (Gottlieb et al. 2002). Para promover a diferenciação celular das neuroesferas, estas foram transferidas a uma placa coberta por poli-D-lisina $(1 \mathrm{mg} / \mathrm{mL}$ ) conforme descrito por (Caldwell et al. 2001, Ostenfeld et al. 2002, Hou et al. 2011, Gu et al. 2013,) e cultivadas com o mesmo meio descrito anteriormente.

\section{RESULTADOS}

Neuroesferas são agregados de células tronco progenitoras, as quais podem ser expandidas em cultivo por um período estendido de tempo e proporcionam um modelo válido para o estudo do desenvolvimento cerebral (Bhattacharyya \& Svendsen 2003). Adicionalmente, tais células são multipotentes podendo gerar neurônios, astrócitos e oligodendrócitos in vitro e in vivo após transplante (Pevny \& Rao 2003).

As células crescem tipicamente em aglomerados, podendo ser replicadas por dissociação mecânica dentro de 7 dias ao atingirem o diâmetro ideal de 100-200 $\mu$ m conforme proposto por Louis \& Reynolds (2010). Na Figura 1 é possível observar neuroesferas com 23 dias em cultivo. Tal como observado por diversos autores, a aderência de neuroesferas ao substrato adequado gera neurônios com sucesso (Caldwell et al. 2001, Ostenfeld et al. 2002, Hou et al. 2011, Gu et al. 2013). 0 processo de diferenciação das neuroesferas em neurônios pode ser realizado com a aspersão das neuroesferas e seu replaqueamento em placas contendo o substrato poli-D-lisina. Na Figura 2 observa-se a migração de fibras do interior da neuroesfera (destacada pelas setas), evidenciando o início do processo de diferenciação celular.

Adicionalmente, foi realizado o cultivo primário de neurônios aviares, destacando-se etapas distintas do cultivo da neuroesfera, conforme observado no material e métodos. Após 24 horas em cultura, os neurônios aderem-se rapidamente ao substrato e distribuem-se uniformemente em toda a superfície tratada da placa. 


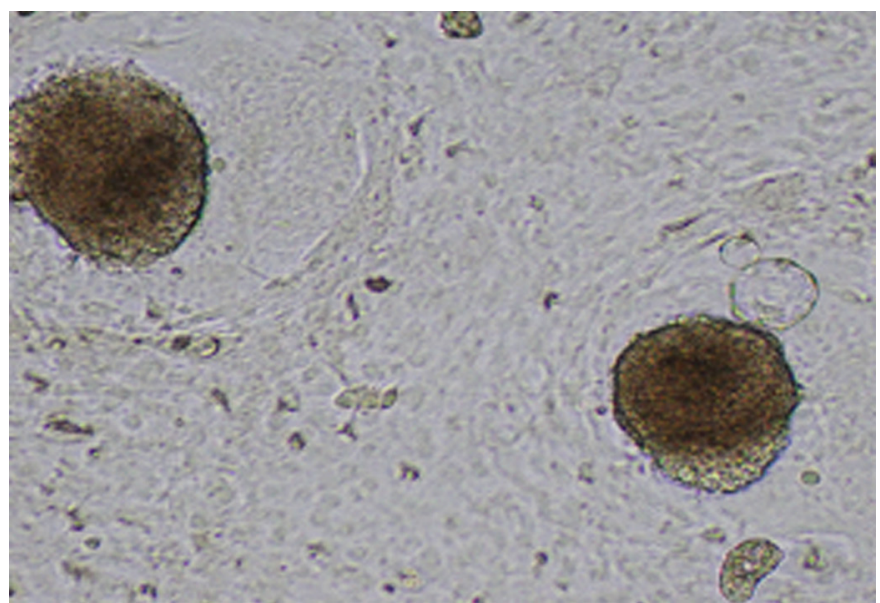

Fig.1. Neuroesferas corticais foram obtidas do embrião aviar com oito dias de incubação. 0 córtex foi removido, sofreu digestão enzimática com tripsina, centrifugado e o pellet ressuspenso em meio contendo 1:1 DMEM/F-12 (Invitrogen) suplementada com 33mM glicose, $4 \mathrm{mM}$ L-glutamina, $1 \%$ suplemento $\mathrm{N}_{2}$ (Invitrogen) e penicilina/estreptomicina $(100 \mathrm{U} / \mathrm{ml}$, Invitrogen). $\mathrm{O}$ aglomerado celular foi mantido em cultivo a $37^{\circ} \mathrm{C}$ e $10 \% \mathrm{CO}_{2}$ durante 23 dias.

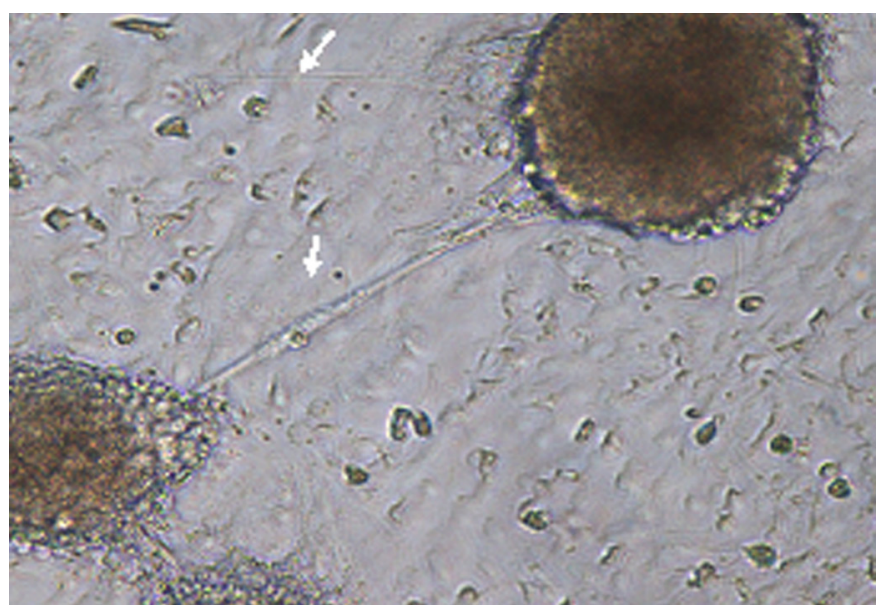

Fig.2. Neuroesfera aderida ao fundo da placa tratada com o substrato poli-D-lisina. As setas evidenciam a presença de fibras migrando da neuroesfera em direção a outro aglomerado celular.

Após 11 dias in vitro, as células alcançam a morfologia típica de células neuronais, as quais mantiveram-se quase que imutáveis por um longo período em cultivo. É comum visualizar o comprimento dos neuritos entre duas a cinco vezes o diâmetro do soma (Weigel et al. 2012) conforme pode ser visualizado nas Figuras 3 a 5.

Weigel et al. (2012) relatam a existência de distintos tipos morfológicos de neurônios, classificados em unipolares e bipolares. Neurônios unipolares apresentam um único neurito longo primário (Fig.3), enquanto os neurônios bipolares (Fig.4) tipicamente possuem dois neuritos quando comparados aos neurônios unipolares. Os neuritos de neurônios adjacentes aparecem frequentemente para formar pequenas redes de interconexões entre dois neurônios (Fig.5).

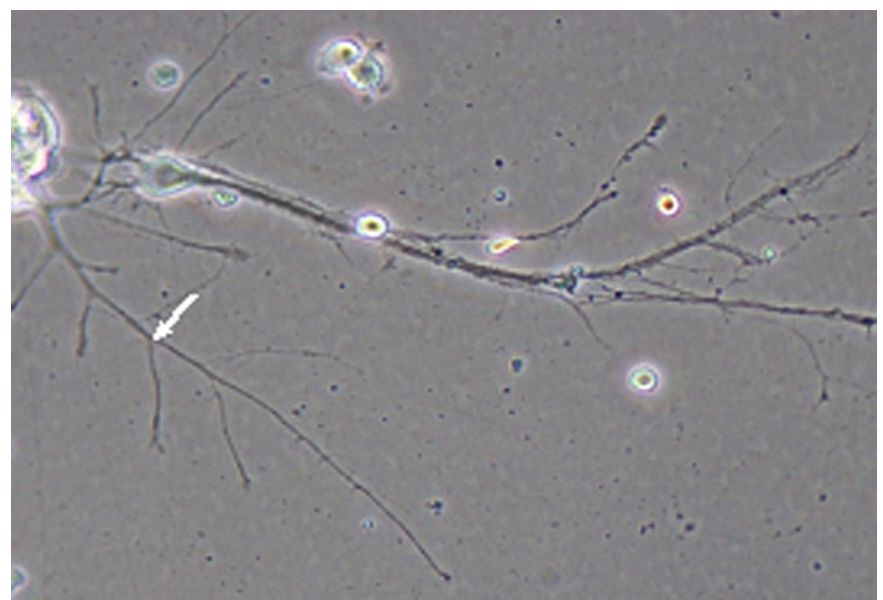

Fig.3. Células neuronais do córtex do embrião aviar após 11 dias em cultivo. Neurônios unipolares foram caracterizados por um único neurito longo primário indicado pela seta branca.

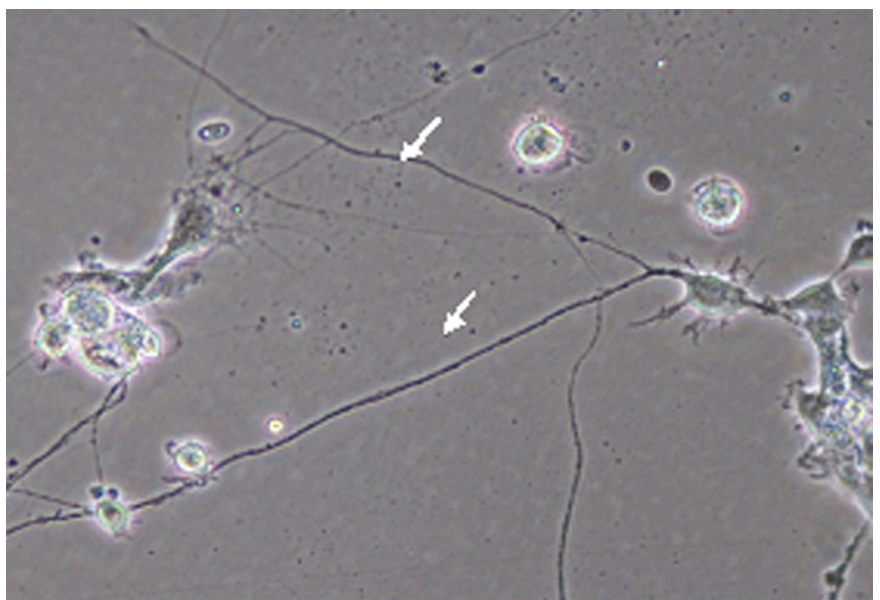

Fig.4. Células neuronais do córtex do embrião aviar após 11 dias em cultivo. Neurônios bipolares tipicamente possuem dois neuritos (setas brancas), quando comparado aos neurônios unipolares estes neuritos eram curtos e bastante volumosos.

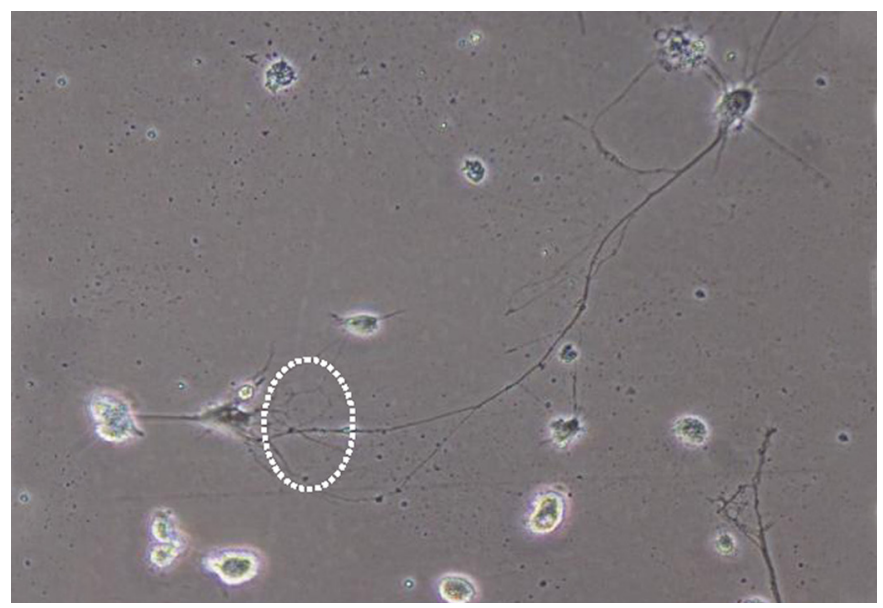

Fig.5. Células neuronais do córtex do embrião aviar após 11 dias em cultivo. Formação de pequenas redes de interconexões entre dois neurônios (indicado pelo circulo tracejado). 


\section{DISCUSSÃO}

O cultivo de células tronco e células neurais diferenciadas são excelentes ferramentas e modelos no estudo da neurogênese e no mecanismo celular para o tratamento de desordens do sistema nervoso (Gu et al. 2013). Entre as vantagens da utilização de neuroesferas há o número ilimitado de células que pode ser gerado a partir de uma única amostra de tecido fetal, estudo do desenvolvimento pré-natal (desenvolvimento cortical), além de estudos específicos da neurogênese (proliferação, migração, diferenciação) (Bhattacharyya \& Svendsen 2003). Além disso, células no interior das neuroesferas podem se diferenciar quando expostas ao substrato e meio adequados, gerando um elevado número de células gliais e neurônios (Caldwell et al. 2001, Bhattacharyya \& Svendsen 2003).

O cultivo neuronal primário isolado de córtex cerebral aviar é amplamente utilizado no estudo do funcionamento cerebral. A neuritogênese é um processo de diferenciação neuronal, a qual ocorre como neuritos nascentes de um soma neuronal pós-mitótico. Caracteriza-se pela elongação das extensões celulares, chamadas de neuritos, que subsequencialmente diferenciam-se em axônios ou em um complexo arbóreo dendrítico (Raad et al. 2012). Nas Figuras 3 a 5 é possível observar as extensões neuríticas em neurônios primários estendendo seus neuritos e estabelecendo sinapses no 11ํ dia após o isolamento (Fig.5). Diversas são as possibilidades de estudos da neuritogênese em cultivo primário aviar. Tal processo é vital para a rede neuronal e contribui amplamente na regeneração do nervo (Raad et al. 2012). Uma anomalia da neuritogênese é uma marca das desordens neurodegenerativas, incluindo a degeneração da retina, epilepsia e doença de Alzheimer.

Aliado ao cultivo neuronal primário há outra ferramenta a neuroproteômica, visando estabelecer uma avaliação global de todo o proteoma neuronal, abordando as alterações dinâmicas e suas interações protéicas (Raad et al. 2012). 0 estudo da VDAC proteína mais abundante da membrana mitocondrial externa e chave no transporte de metabólitos e morte celular, demonstrou um padrão de complexação proteico diferenciado (Crepaldi et al. 2011), ou seja um interactoma proteico peculiar na espécie aviar em relação às espécies bovina e murina (Crepaldi et al. 2013), bem como uma proporção diferenciada de isoformas da VDAC1 e VDAC2 em relação as outras espécies (Poleti et al. 2010), além da presença de alterações pós-traducionais, destacando-se a fosforilação, em suas isoformas nesta espécie (Vitale et al. 2012).

A metodologia estabelecida no presente estudo será utilizada para identificação das variáveis proteômicas descritas acima, bem como, das alterações que podem ocorrer com as mesmas, em situações as mais variadas. Cite-se por exemplo, o efeito da indução da apoptose por estaurosporina. Outras possíveis aplicações deste sistema estariam associados aos possíveis efeitos moduladores da interação hexoquinase-VDAC por substâncias como a glicose-6-P (desligamento da hexoquinase), DIDS (bloqueio da VDAC), Ruthenium red e Poliânion de Koenig (estabilizadores do canal em estado fechado).

Tomadas em conjunto, devido à complexidade das doenças neurodegenerativas, uma análise meticulosa das alterações/interações protéicas das células neuronais em cultivo pode auxiliar a decifrar o interactoma de proteínas chaves na neurogênese da doença. Adicionalmente, estudos proteomicos similares são realizados na diferenciação em células neuroprogenitoras e/ou células tronco neurais em neurônios utilizando diferentes plataformas proteomicas e identificando um repertório diferenciado de proteínas neuronais especificas (Raad et al. 2012).

\section{CONCLUSÃO}

Descrevemos um método para o isolamento de neurônios e neuroesferas em cultura de córtex cerebral de frangos. Tal modelo "in vitro" pode ser utilizado em estudos de expressão proteica neuronal diferencial, bem como de interações entre proteínas.

Agradecimentos.- Amostras foram cedidas gentilmente pela empresa Globoaves. Esse projeto teve suporte da Fundação de Amparo à Pesquisa do Estado de São Paulo (Proc. 2010/05560-6). Carla Rossini Crepaldi foi bolsista nível mestrado da Fundação de Amparo à Pesquisa do Estado de São Paulo (Proc. 2009/06687-2).

\section{REFERÊNCIAS}

Ahlemeyer B. \& Vogt E.B. 2005. Optimized protocols for the simultaneous preparation of primary neuronal cultures of the neocortex, hippocampus and cerebellum from individual newborn (P0.5) C57Bl/6J mice. J. Neuros. Meth. 149:110-120.

Bhattacharyya A. \& Svendsen C.N. 2003. Human neural stem cells: a new tool for studying cortical development in Down's syndrome. Genes Brain Behav. 2:179-186.

BeltrandelRio H. \& Wilson J.E. 1991. Hexokinase of rat brain mitochondria: relative importance of adenylate kinase and oxidative phosphorylation as sources of substrate ATP, and interaction with intramitochondrial compartments of ATP and ADP. Arch. Biochem. Biophys. 286:183-194.

Caldwell M.A., He X., Wilkie N., Pollack S., Marshall G., Wafford K.A. \& Svendsen C.N. 2001. Growth factors regulate the survival and fate of cells derived from human neurospheres. Nat. Biotechnol. 19:475-479.

Cerqueira César M. \& Wilson J.E. 1995. Application of a double isotopic labeling method to a study of the interaction of mitochondrially bound rat brain hexokinase with intramitochondrial compartments of ATP generated by oxidative phosphorylation. Arch. Biochem. Biophys. 324:9-14.

Cerqueira César M. \& Wilson J.E. 1998. Further studies on the coupling of mitochondrially bound hexokinase to intramitochondrially compartmented ATP, generated by oxidative phosphorylation. Arch. Biochem. Biophys. 350:109-117.

Cerqueira César M. \& Wilson J.E. 2002. Functional characteristics of hexokinase bound to the type A and type B sites of bovine brain mitochondria. Arch. Biochem. Biophys. 397:106-112.

Cerqueira César M. \& Wilson J.E. 2004. All three isoforms of the voltagedependent anion channel (VDAC1, VDAC2, and VDAC3) are present in mitochondria from bovine, rabbit, and rat brain. Arch. Biochem. Biophys. 422:191-196.

Cheng E.H.Y., Sheiko T.V., Fisher J.K., Craigen W.J., \& Korsmeyer S.J. 2003. VDAC2 inhibits BAK activation and mitochondrial apoptosis. Science 301:513-517.

Crepaldi C.R., Munin F.S., Vitale P.A.M. \& Cerqueira César M. 2011. Análise interactômica da VDAC (voltage dependent anion selective channel) nos cérebros aviar, bovino e murino. Pesq. Vet. Bras. 31:1031-1038.

Crepaldi C.R., Vitale P.A.M., Tesch A.C., Laure H.J., Rosa J.C. \& Cerqueira César M. 2013. Application of 2D BN/SDS PAGE coupled with mass spectrometry for identification of VDAC-associated protein complexes related to mitochondrial binding sites for type I brain hexokinase. Mitochondrion 13(6):823-830. 
Escartin C. \& Rouach N. 2013. Astroglial networking contributes to neurometabolic coupling. Front. Neuroenergetics 5:1-4.

Fabene P.F., Laudannab C. \& Constantinb G. 2013. Leukocyte trafficking mechanisms in epilepsy. Mol. Immunol. 55:100-104.

Finsterer J. \& Mahjoub S.Z. 2013. Presentation of adult mitochondrial epilepsy. Seizure 22:119-123.

Gottlieb I.D. 2002. Large-scale sources of neural stem cells. Annu. Rev. Neurosci. 25:381-407.

Gu H., Yu S.P., Gutekunst C.A., Gross R.E. \& Wei L. 2013. Inhibition of the Rho signaling pathway improves neurite outgrowth and neuronal differentiation of mouse neural stem cells. Int. J. Physiol. Pathophysiol. Pharmacol. 5:11-20.

Hou L., Jin D., Gu E., Pu Y., Li F., Guan W. \& Ma Y. 2011. Isolation and characterization of duck embryonic neural stem and progenitor cells. Poult Sci. 90:609-617.

Jiang W., Du B., Chi Z., Ma L., Wang S., Zhang X., Wu W., Wang X., Xu G. \& Guo C. 2007. Preliminary explorations of the role of mitochondrial proteins in refractory epilepsy: some findings from comparative proteomics. J. Neurosci. Res. 85:3160-3170.

Kearns S.M., Laywell E.D., Kukekov V.K. \& Steindler D.A. 2003. Extracellular matrix effects on neurosphere cell motility. Experim. Neurol. 182:240244.

Kim H.J. \& Magrané J. 2011. Isolation and culture of neurons and astrocytes from the mouse brain cortex. Methods Mol. Biol. 793:63-75.

Kroemer G., Galluzzi L. \& Brenner C. 2007. Mitochondrial membrane permeabilization in cell death. Physiol. Rev. 87:99-163.

Loscher W. \& Potschka H. 2002. Role of multidrug transporters in pharmacoresistance to antiepileptic drugs. J. Pharmacol. Exp. Ther. 301:7-14.

Louis S.A. \& Reynolds B.A. 2010. Neurosphere and neural colony-forming cell assays, p.1-28. In: Doering L.C. (Ed.), Protocols for Neural Cell Culture. $4^{\text {th }}$ ed. Humana Press, Canada.

Margoliash D., Van Drongelen W. \& Kohrman M. 2010. Introducing songbirds as a model system for epilepsy research. J. Clin. Neurophysiol. 27:433-437.

Monnerie H., Boespflug-Tanguy O., Dastugue B. \& Meiniel A. 1997. An in vitro cell culture system for the aggregation of embryonic chick central nervous system neurons. Brain Res. Brain Res. Protoc. 1:344-346.
Monteiro R., Adams V., Keys D. \& Platt S.R. 2012. Canine idiopathic epilepsy: prevalence, risk factors and outcome associated with cluster seizures and status epilepticus. J. Small Anim. Pract. 53:526-530.

Ostenfeld T., Tai Y.T., Martin P., Déglon N., Aebischer P. \& Svendsen C.N. 2002. Neurospheres modified to produce glial cell line-derived neurotrophic factor increase the survival of transplanted dopamine neurons. J. Neurosci. Res. 69:955-965.

Pastorino J.G. \& Hoek J.B. 2008. Regulation of hexokinase binding to VDAC. J. Bioenerg. Biomembr. 40:171-182.

Pevny L. \& Rao M.S. 2003. The stem-cell menagerie. Trends Neurosci. 26:351-359.

Pohlmann-Eden B. \& Weaver D.F. 2013. The puzzle(s) of pharmacoresistant epilepsy. Epilepsia 2:1-4.

Poleti M., Tesch A., Crepaldi C., Souza G., Eberlin M. \& Cerqueira César M. 2010. Relationship Between expression of voltage-dependent anion channel (VDAC) isoforms and type of hexokinase binding sites on brain mitochondria. J. Mol. Neurosci. 41:48-54.

Raad M., El Tal T., Gul R., Mondello S., Zhang Z., Boustany R. M., Guingab J., Wang K.K. \& Kobeissy F. 2012. Neuroproteomics approach and neurosystems biology analysis: ROCK inhibitors as promising therapeutic targets in neurodegeneration and neurotrauma. Electrophoresis 33:36593668.

Sacktor B., Wilson J.E. \& Tiekert C.G. 1966. Regulation of glycolysis in brain, in situ, during convulsions. J. Biol. Chem. 241:5071-5075.

Scorza F.A., Albuquerque R., Arida R.M., Schmidt B., Almeida A.C.G., Scorza C.A. \& Cavalheiro E.A. 2009. Could sudden death syndrome (SDS) in chickens (Gallus gallus) be a valid animal model for sudden unexpected death in epilepsy (SUDEP)? Med. Hypotheses 73:67-69.

Sowers L.P., Massey C.A., Gehlbach B.K., Granner M.A. \& Richerson G.B. 2013. Sudden unexpected death in epilepsy: Fatal post-ictal respiratory and arousal mechanisms. Respir. Physiol. Neurobiol. 189(2):315-323.

Vitale P.A.M., Crepaldi C.R., Tesch A.C., Albuquerque R. \& César M.C. 2012. Purificação e caracterização da VDAC de mitocôndrias corticais aviares: identificação de modificações pós-traducionais nas porinas neuronais murinas e aviares. Pesq. Vet. Bras. 32:1361-1366.

Weigel S., Schulte P., Bräunig S.M.P. \& Offenhäusser A. 2012. Locust primary neuronal culture for the study of synaptic Transmission. J. Mol. Histol. 43:405-419. 